DOI: $10.5543 /$ khd.2020.08769

Turk J Cardiovasc Nurs 2020;11(25):82-89

\title{
Akut Koroner Sendrom Geçiren Hastalarda Risk Faktörlerinin Belirlenmesi
}

\author{
(D) Aynur Kaynar Şimşek, (1) Şule Ecevit Alpar \\ Marmara Üniversitesi Sağlık Bilimleri Fakültesi, Hemşirelik Bölümü, İstanbul
}

\begin{abstract}
Özet
Amaç: Bu araştırma akut koroner sendrom (AKS) ile başvuran hastalarda koroner arter hastalığı (KAH) risk faktörlerini belirlemek amacıyla tanımlayıcı olarak yapıldı.

Yöntemler: Araştırmaya bir üniversite hastanesinde 2018- 2019 tarihleri arasında acilden ya da poliklinikten AKS ile kardiyoloji kliniğine yönlendirilen 120 hasta dahil edildi. Veriler Hasta İzlem Anketi ile toplandı.

Bulgular: Hastaların yaş ortalaması 54.71 \pm 9.8 olup (kadın: $54.82 \pm 9.36$; erkek: $54.69 \pm 9.91), \% 85.8$ 'i $(n=103)$ erkekti ve \%64.2'sinin ( $\mathrm{n=43)}$ toplam aylık geliri 2000-5000 TL idi. Hastalar KAH risk faktörleri açısından değerlendirildiğinde; \%82.5'inin fiziksel aktivite yapmadığı, \%76.6'sının sistemik bir hastalığının olduğu ve KAH olan bireylerin \%80.7'sinin tanısını bilmediği, \%69.2'sinin (n:83) ailesinde KAH öyküsünün olduğu, \%66.7'sinin stresini kontrol etmede yetersiz kaldığı, \%56.7'sinin sigara kullandığı tespit edildi. Risk faktörleri cinsiyete göre karşılaştıııldığında, kadınların beden kitle indeksi (31.63) ve stresi konturol etmede yetersiz kalma durumu (\%94.1) erkeklere göre yüksek bulundu $(p<0.005)$. Ayrıca risk faktörlerinin görülme sıklığı cinsiyete göre karşılaştıııldığında kadınlarda stres (\%94.1) birinci sırada iken, erkeklerde hiperkolesteroleminin (\%92.0) birinci sırada yer aldığı tespit edildi.

Sonuç: AKS geçiren hastaların, KAH risk faktörlerini (cinsiyet, yaş, sistemik hastalıklara sahip olmak, sigara içmek, yetersiz fiziksel aktivite, stres, dislipidemi, beden kitle indeksinin yüksek olması) taşıdıkları saptandı. Ayrıca düşük gelirli olmak, KAH'nın farkındalığının olmaması AKS geçirme riskini artırdığı sonucuna varıldı.
\end{abstract}

Anahtar sözcükler: Fiziksel aktivite; hipertansiyon; hemşirelik.

\section{Determination of Risk Factors In Patients With Acute Coronary Syndrome}

\begin{abstract}
Objective: This descriptive study was conducted to determine the risk factors of coronary artery disease (CAD) in patients presenting with acute coronary syndrome (ACS).

Methods: 120 patients who were referred to the cardiology clinic from the emergency or outpatient clinic with ACS between 2018 and 2019 in a university hospital were included in this study. The data were collected with Patient Monitoring Questionnaire.

Results: The patients mean age was 54.71 (female: 54.82; male: 54.69), 85.8\% of them were male ( $n=103)$ and $64.2 \%$ of them $(n=43)$ had a total monthly income of 2000-5000TL. When patients are evaluated in terms of CAD risk factors, it is found out that $82.5 \%$ had no physical activity, $80.7 \%$ did not even know that their diagnosis was CAD, $76.6 \%(n=92)$ had a diagnosis of a systemic disease, $69.2 \%$ had a family history of CAD, $66.7 \%$ had remained inadequate in stress control, 56,7\% smoked, When the risk factors were compared by gender, the body mass index of women (31.63) and insufficiency in stress controll (94.1\%)
\end{abstract}

İletişim (Correspondence): Aynur Kaynar Şimşek. Marmara Üniversitesi Sağlık Bilimleri Fakültesi, Başıüyük Cd. No: 9, 34854 Maltepe,

34000 İstanbul

Telefon (Phone): +90 5304642743 E-Posta (E-mail): aynurkaynarsimsek@hotmail.com

Başvuru Tarihi (Submitted Date): 07.02.2020 Kabul Tarihi (Accepted Date): 20.08.2020

OCopyright 2020 by Turkish Society of Cardiology - Available online at www.anatoljcardiol.com

OPEN ACCESS This work is licensed under a Creative Commons Attribution-NonCommercial 4.0 International License. 


\begin{abstract}
were higher than men $(\mathrm{p}<0.005)$. In addition, when the frequency of risk factors was compared by gender, it was found that stress (94.1\%) was in the first place in woman while hypercholesterolemia (92.0\%) was in the first place in men.

Conclusion: As a result of this study it is observed that the patients with Acute Coronary Syndrome carry the CAD risk factors (gender, aging, having a systemic disease, smoking, inadequate physical activity, stess, dyslipidemia, higher BMI). In addition, it was concluded that low monthly income and lack of CAD awareness increase CAD risk.

Keywords: Physical activity; hypertension; nursing.

Cite this article as: Kaynar Şimşek A, Ecevit Alpar Ş. Determination of Risk Factors In Patients With Acute Coronary Syndrome. Turk J Cardiovasc Nurs 2020;11(25):82-89.
\end{abstract}

$\mathrm{H}$ er yıl ölen kişi sayısını ve ölüm nedenlerini ölçmek, bir ülkenin sağlık sisteminin etkinliğini değerlendirmede, hastalıkların ve yaralanmaların insanları nasıl etkilediğini belirlemede en etkili yöntemdir. ${ }^{[1]}$ Bu amaçla yapılan çalışmalardan biri olan Küresel Hastalık Yükü Çalışması'nın 2017 bulgularında (Global Burden of Disease study, 2017) kardiyovasküler hastalıklara bağlı ölümler; bu ölümlerin içerisinde ise iskemik kalp hastalığına bağlı ölümler, ölüm nedenlerinin birinci sırasında yer almaktadır. Ülkemizde de bu durum benzerdir. ${ }^{[2]}$ Türkiye İstatistik Kurumu (2018) ölüm istatistikleri verilerine göre; kardiyovasküler hastalıklara bağlı ölümler ölüm nedenleri arasında birinci sırada iken; kardiyovasküler hastalıkların içerisinde ise iskemik kalp hastalıklarına bağlı ölümler birinci sırada yer almaktadır. ${ }^{[1]}$ Koroner ateroskleroz çoğunlukla koroner arter hastalığına (KAH) yol açsa da koroner damarlarda gelişen tıkayıcı lezyonlar, aterosklerotik plaklar miyokartta akut iskemiye neden olabilmektedir. Kısa sürede gelişen ve miyokart dokusunu tehdit eden iskemik tabloların tamamı akut koroner sendrom (AKS) olarak tanımlanmaktadır. Akut koroner sendromda ani ölüm ve miyokart nekrozu riski yüksektir. [3-5] Bu riski azaltmanın en etkin yolu ise risk faktörlerini tanımlamak ve AKS gelişmeden önce kontrol altına almaktır. Eğer AKS geçirme riski olan bireyler belirlenip bu bireylerin risk faktörleri kontrol altına alınırsa ölümcül olan ve olmayan iskemik olaylara maruz kalmaları da önlenebilir. Böylece kişilerin ve toplumun kardiyovasküler hastalıklara bağlı ölüm oranları azaltılabilir. ${ }^{[6,7]}$

\section{Gereç ve Yöntem}

\section{Araştırmanın Amacı ve Tipi}

Bu araştırma AKS ile başvuran hastalarda KAH risk faktörlerini belirlemek amacıyla tanımlayıcı olarak yapıldı.

\section{Araştırmanın Evren ve Örneklemi}

Araştırma bir üniversite hastanesinde 2018-2019 tarihleri arasında yapıldı. Bu tarihler arasında haftanın üç günü (Salı, Perşembe ve Cuma) kardiyoloji kliniğine (acil ya da poliklinikten) başvuran tüm hastalar (183) değerlendirildi. Bu hastalardan ilk kez AKS geçiren (daha önceden AKS geçiren hastalarda tedavinin risk faktörlerini maskelemesini engellemek amacıyla), Türkçe konuşan ve anlayan, çalışmaya katılmayı kabul eden 120 hasta çalışmaya dahil edildi.

\section{Veri Toplama Yöntemi ve Araçları}

Veriler araştırmacı tarafından hazırlanan, hastaların sosyodemografik özelliklerini, klinik ve laboratuvar bulgularını içeren Hasta İzlem Anketi ile toplandı. Araştırmacı tarafından literatür incelenmesi, bilgi ve gözlemleri doğrultusunda hazırlanan bu anket, hastaların sosyodemografik özelliklerini, alışkanlıklarını, daha önceki tıbbi geçmişini, şu anki sağlık durumunu belirlemek amacıyla 28 sorudan oluşmaktaydı. Hastalarla yüz yüze görüşülerek, dosyalar incelenerek ve hastane sisteminden kan sonuçlarına ulaşılarak veriler toplandı.

Hastanın özgeçmişinde hekim önerisiyle antihipertansif ilaç kullanıyor olmasıyla (eski tanı) veya takiplerinde sistolik kan basıncının 140 mmHg'dan, diastolik kan basıncının 90 mmHg'dan yüksek olması nedeniyle antihipertansif ilaç tedavisine başlanmış olmasıyla (yeni tanı) hipertansiyon (HT) tanımlandı. Hastanın özgeçmişinde hekim önerisiyle antidiabetik ilaç kullanıyor olmasıyla (eski tanı) veya $\mathrm{HbA} 1 \mathrm{c}$ düzeyinin $\% 6.5$ (47 mmol/mol) veya daha yüksek olmasıyla (yeni tanı) diabetes mellitus (DM) tanımlandı. Hastaların öz geçmişinde KAH tanısı almış ve bu amaçla ilaç kullanıyor olmasıyla (eski tanı) veya yapılan tetkikler sonucu koroner arterlerde darlığın \%50 ve daha fazla olmasıyla (yeni tanı) KAH tanımlandı. Birinci derecede akrabalarında erkeklerde 55 yaşından, kadınlarda 65 yaşından önce KAH saptanmasıyla aile öyküsü tanımlandı. ${ }^{[8]}$ Lipit parametreleri için ATP 3 ( ATP III Guidelines) ${ }^{[9]}$ klavuzunda kabul edilen hedef değerler baz alındı. Düşük yoğunluklu lipoprotein (LDL) açlık plazma seviyesinin $100 \geq \mathrm{mg} / \mathrm{dL}$ veya total kolesterol (T-K) seviyesinin ise $200 \geq \mathrm{mg} / \mathrm{dL}$ olmasıyla hiperkolesterolemi tanımlandı. Trigliserid açlık plazma seviyesinin $150 \geq \mathrm{mg} / \mathrm{dL}$ olmasıyla hipertrigliseridemi tanımlandı. Yüksek dansiteli lipoprotein (HDL) plazma seviyesinin $\leq 40 \mathrm{mg} / \mathrm{dL}$ olmasıyla HDL düşüklüğü tanımlandı. Sigara içiciliği, güncel sigara içiciliği olarak tanımlandı. 'Haftada en az üç kez 30 dakika ve/veya daha uzun süreli egzersiz yapmama, ${ }^{[8]}$ fiziksel aktivitede yetersizlik olarak tanımlanırken; bireyin stresini 
kontrol edemediğini ifade etmesiyle stresi kontrol etmede yetersiz kalma durumu tanımlandı.

\section{Araştırma Verilerinin Değerlendirilmesi}

Verilerin analizi SPSS 18.0 (Statistical Package for Social Sciencess) paket programı kullanılarak yapıldı. Veriler analiz edilirken nicel değişkenler için tanımlayıcı istatistikler; ortalama, standart sapma, minimum ve maksimum değerleri olarak ifade edilirken, nitel değişkenler sayı ve yüzde olarak ifade edildi. Nicel değişkenler bakımından grup ortalamalarını karşılaştırmada Student's T-Testi ve değişkenlerin homojen dağılmaması durumunda Mann-Whitney $U$ testi kullanıldı. Gruplar ile nitel değişkenler arasındaki ilişkiyi belirlemede ise Ki-Kare Testi yapıldı. Hesaplamalarda istatistiki anlamlılık düzeyi $\% 5$ olarak alındı.

\section{Araştırmanın Etik Boyutu}

Araştırmanın yapılabilmesi için etik kurul onayı (Tarih: 04. 05.2018; Protokol Kodu: 09. 2018. 362) ve kurum izni alın- masını takiben verilerin toplanmasına başlandı. Araştırmaya alınacak hastalara araştırma hakkında bilgi verilerek onayları alındı ve aydınlatılmış onam formları imzalatıldı. $\mathrm{Bu}$ araştırma, helsinki deklerasyonuna ve iyi klinik uygulamalar etiğine uygun şekilde planlandı ve yürütüldü.

\section{Bulgular}

Akut koroner sendrom tanısı alan hastaların \%85.8'i $(n=103)$ erkek, \%14.2'si $(n=17)$ kadındı. Yaş ortalaması 54.71 \pm 9.8 olarak (kadın: 54.82 \pm 9.36 ; erkek: $54.69 \pm 9.91$ ) bulundu. Hastaların \%64.2'sinin ( $n=43)$ hanesine giren toplam aylık gelirin 2000-5000 TL arasında olduğu, \%76.6'sının ( $n=92)$ sistemik hastalığının olduğu tespit edildi. Sistemik hastalıklardan, HT tanısı almış hastaların \%84.4'ünün ( $n=38)$, DM tanısı almış hastaların \%55.6'sının ( $n=20)$, KAH tanısı almış hastaların ise sadece \%19.3'ünün $(n=17)$ tanısını önceden bildiği tespit edildi. Cinsiyete göre yaş, haneye giren toplam aylık gelir ve sistemik hastalık varlığı karşılaştıılldığında fark bulunmadı ( $p>0.05$ ) (Tablo 1).

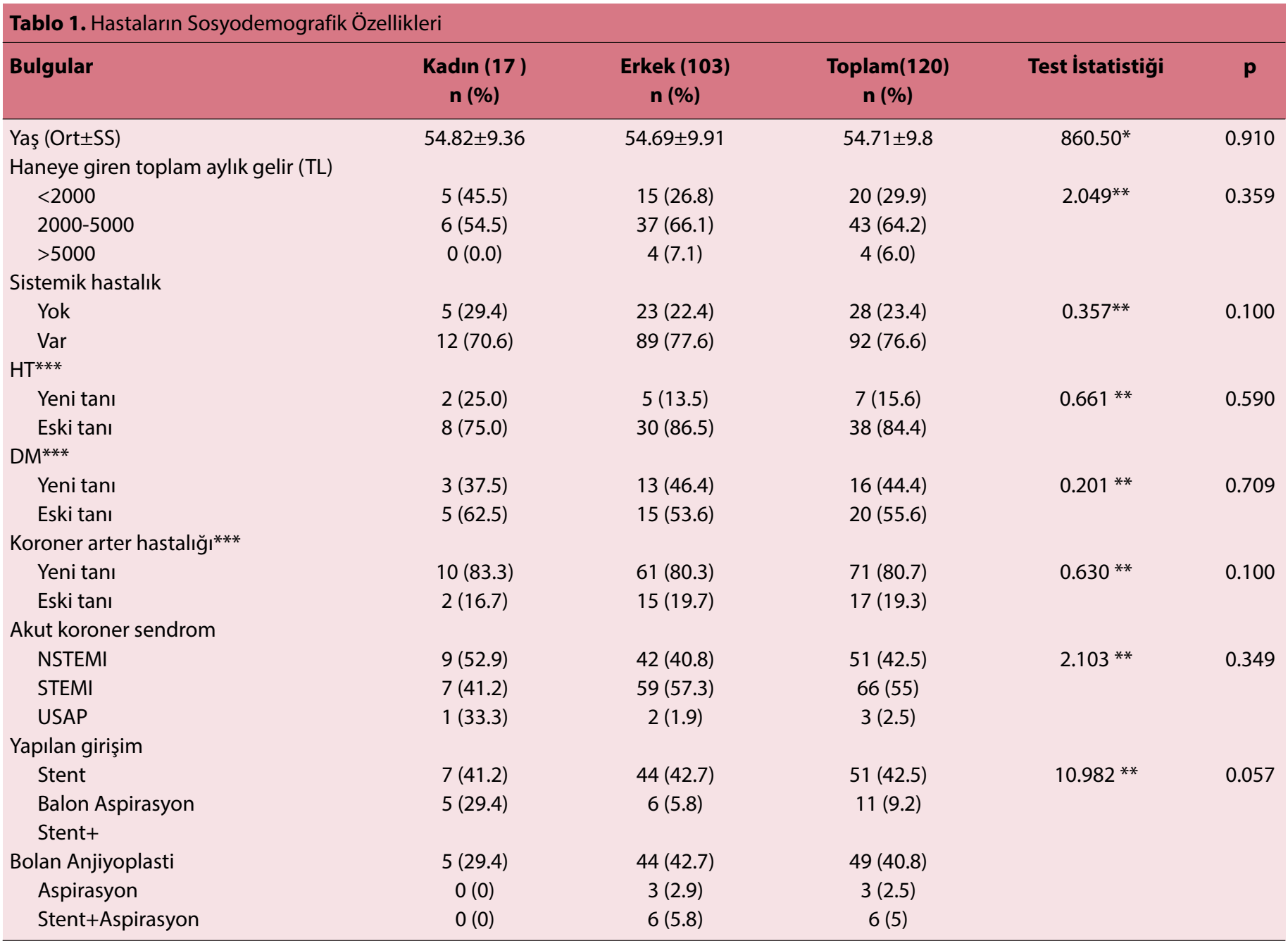

*Student's T- Testi T- Testi; **Ki-kare testi; ***Sadece ek bir sistemik hastalığı olan vakalar analize alınmıştır. 
Akut koroner sendromun tipi açısından bulgular değerlendirildiğinde, hastaların \%55'inin ( $n=66)$ ST yükselmesi olan miyokart infarktüsü (STEMI) tanısı almış olduğu ve $\% 42.5$ 'ine $(n=51)$ stent takıldığı tespit edildi. Cinsiyet açısından bu parametreler karşılaştırıldığında fark bulunmadı (p>0.05) (Tablo 1).

Hastaların \%82.5'inin ( $n=99)$ fiziksel aktivite yapmadığı, \%69.2'sinin ( $n=83$ ) ailesinde koroner arter hastalık öyküsünün olduğu, \%66.7'sinin ( $\mathrm{n}=80)$ stresini kontrol etmede yetersiz kaldığı (kadın: \%94.1; erkek: \%62.1), \%56.7'sinin (n:68) sigara içtiği, \%14.2'sinin ( $n=17)$ alkol kullandığı tespit edildi. Hastaların beden kitle indeksi ortalaması $27.49 \mathrm{~kg} / \mathrm{m}^{2}$ (kadın: $31.63 \mathrm{~kg} / \mathrm{m}^{2}$; erkek: $27.08 \mathrm{~kg} / \mathrm{m}^{2}$ ) olarak bulundu. İki cinsiyet arasında sigara içme durumu, alkol kullanma durumu, aile öyküsü, fiziksel aktivite yapma durumu açısından fark bulunmazken ( $p>0.05)$; kadınların stresi kontrol etmede yetersiz kalma durumu ve benden kitle indeksi erkeklere oranla yüksek bulundu $(p<0.05)$ (Tablo 2$)$.

Kan sonuçları incelendiğinde; HDL ortalamasının $39 \mathrm{mg} /$ dL (kadın: $41.07 \pm 6.66$, erkek: $38.34 \pm 6.59$ ), T-K ortalaması-

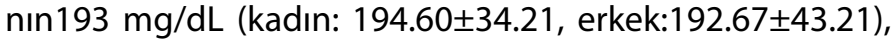
LDL ortancasının 123 mg/dL (kadın: 126; erkek: 122), Trigiliserid ortancasının 148 mg/dL (kadın: 143; erkek: 149) olduğu tespit edildi. Bu değerler cinsiyete göre karşılaştırıldığında benzer sonuçlar elde edildi ve fark bulunmadı $(p>0.005)$ (Tablo 2).

$\mathrm{KAH}$ risk faktörlerinin görülme sıklığı açısından veriler incelendi. Kadınlarda stres (\%94.1), beden kitle indeksinin $25 \mathrm{~kg} / \mathrm{m}^{2 \prime}$ den yüksek olması (\%94.0) ilk sırada yer alırken, erkeklerde ise hiperkolesteroleminin (\%92.0) ilk sırada yer aldığı tespit edildi (Tablo 3).

\section{Tartışma}

Akut koroner sendrom tanısı alan hastaların büyük çoğunluğu (\%85.8) erkek idi (Tablo 1). Baltacı ve ark., ${ }^{[10]}$ AKS geçiren hastaların \%74.2'sinin, Usta ve ark., ${ }^{[1]]} \% 62.7$ 'sinin, Özen ve ark., ${ }^{[12]} \% 72.1^{\prime}$ inin erkek olduğunu bildirmiştir. Bu bulgular çalışmamızla paralellik göstermektedir. Huang ve ark., ${ }^{[13]}$ menopoz öncesi kadınlarda KAH insidansının erkeklere ve menopoz sonrası kadınlara göre düşük oldu-

\begin{tabular}{|c|c|c|c|c|c|}
\hline Bulgular & $\begin{array}{l}\text { Kadın (17) } \\
\text { n (\%) }\end{array}$ & $\begin{array}{l}\text { Erkek (103) } \\
\qquad \mathrm{n}(\%)\end{array}$ & $\begin{array}{c}\text { Toplam (120) } \\
n(\%)\end{array}$ & Test İstatistiği & $\mathbf{p}$ \\
\hline \multicolumn{6}{|l|}{ Sigara kullanma } \\
\hline Evet & $6(35.3)$ & $62(60.2)$ & $68(56.7)$ & \multirow[t]{2}{*}{3.684 * } & \multirow[t]{2}{*}{0.670} \\
\hline Hayır & $11(64.7)$ & 41 (39.z) & $52(43.3)$ & & \\
\hline \multicolumn{6}{|l|}{ Alkol kullanma } \\
\hline Evet & $0(0)$ & $17(16.5)$ & $17(14.2)$ & \multirow{2}{*}{3.269 * } & \multirow[t]{2}{*}{0.126} \\
\hline Hayır & $17(100)$ & $86(83.5)$ & $103(85.8)$ & & \\
\hline \multicolumn{6}{|l|}{ Aile öyküsü } \\
\hline Var & $14(82.4)$ & $69(67.0)$ & $83(69.2)$ & \multirow[t]{2}{*}{$1.615 *$} & \multirow[t]{2}{*}{0.264} \\
\hline Yok & $3(17.6)$ & $34(33.0)$ & $37(30.8)$ & & \\
\hline \multicolumn{6}{|l|}{ Fiziksel aktivite } \\
\hline Evet & $2(11.8)$ & $19(18.4)$ & $21(17.5)$ & \multirow[t]{2}{*}{$0.451^{*}$} & \multirow[t]{2}{*}{0.734} \\
\hline Hayır & $15(88.2)$ & $84(81.6)$ & $99(82.5)$ & & \\
\hline \multicolumn{6}{|l|}{ Stresi kontrolü } \\
\hline Evet & $1(5.9)$ & 39 (37.9) & 40 (33.3) & \multirow[t]{2}{*}{$6.716 *$} & \multirow[t]{2}{*}{0.011} \\
\hline Hayır & $16(94.1)$ & $64(62.1)$ & $80(66.7)$ & & \\
\hline Diğer özellikler & Ort $\pm S S$ & Ort $\pm S S$ & & Test İstatistiği & $\mathbf{p}$ \\
\hline $\mathrm{HDL}(\mathrm{mg} / \mathrm{dL})$ & $41.07 \pm 6.66$ & $38.34 \pm 6.59$ & $39 \pm 6.71$ & $502.50^{* *}$ & 0.156 \\
\hline \multirow[t]{2}{*}{ T- kolesterol (mg/dL) } & $194.60 \pm 34.21$ & $192.67 \pm 43.21$ & $193 \pm 43.02$ & $618.00^{* *}$ & 0.744 \\
\hline & $\begin{array}{c}\text { Ortanca } \\
\text { (Min-Mak) }\end{array}$ & $\begin{array}{c}\text { Ortanca } \\
\text { (Min-Mak) }\end{array}$ & & Test İstatistiği & $\mathbf{p}$ \\
\hline Trigiliserid (mg/dL) & $143(52-313)$ & $149(47-438)$ & $148(47-438)$ & $642^{* *}$ & 0.0977 \\
\hline & $126(31-159)$ & $122(19-400)$ & $123(19-400)$ & $638.50 * *$ & 0.895 \\
\hline \multirow[t]{2}{*}{ Beden Kitle İndeksi $\left(\mathrm{kg} / \mathrm{m}^{2}\right)$} & 31.63 & 27.08 & 27.49 & \multirow[t]{2}{*}{$496 * *$} & \multirow[t]{2}{*}{0.004} \\
\hline & $(23.42-40.04)$ & $(19.94-42.94)$ & $(19.94-42.94)$ & & \\
\hline
\end{tabular}

**Ki-Kare testi; **Mann Whitney U Testi. 


\begin{tabular}{|c|c|c|c|c|}
\hline & \multicolumn{2}{|c|}{ Kadın $(n=17)$} & \multicolumn{2}{|c|}{ Erkek $(n=103)$} \\
\hline & Risk Faktörü & (\%) & Risk Faktörü & (\%) \\
\hline 1. Sırada & Stres & 94.1 & Hiperkolesterolemi & 92.0 \\
\hline 2. Sırada & $\mathrm{BKI}>25 \mathrm{~kg} / \mathrm{m}^{2}$ & 94.0 & $\mathrm{BKI}>25 \mathrm{~kg} / \mathrm{m}^{2}$ & 84.5 \\
\hline 3. Sırada & Hiperkolesterolemi & 93.3 & Fiziksel aktivite yetersizliği & 81.6 \\
\hline 4. Sırada & Fiziksel aktivite yetersizliği & 88.2 & Sistemik Hastalık & 77.6 \\
\hline 5. Sırada & Sistemik Hastalık & 70.6 & Stres & 62.1 \\
\hline 6. Sırada & HDL düşüklüğü & 53.3 & HDL düşüklüğü & 60.9 \\
\hline 7. Sırada & Hipertrigiliseridemi & 46.7 & Sigara kullanma & 60.0 \\
\hline 8. Sırada & Sigara kullanma & 35.0 & Hipertrigiliseridemi & 48.8 \\
\hline 9. Sırada & Alkol Kullanma & 0 & Alkol kullanma & 16.5 \\
\hline
\end{tabular}

ğunu bildirmiştir. Guo ve ark., ${ }^{[14]}$ ise, KAH olan bireylerin serum östrojen düzeylerini, aynı yaştaki sağlıklı bireylerden düşük bulmuşlar ve östrojen hormonunun kadınlarda menopoz dönemine kadar atereoskleroza karşı koruyucu rol oynadığını bildirmişlerdir. AKS geçiren hastaların büyük çoğunluğunun erkek olması ve literatür bilgilerinden de yola çıkılarak, erkeklerin kadınlara oranla AKS geçirme riskinin daha yüksek olduğunu düşündürdü.

Hastaların yaş ortalaması $54.71 \pm 9.8$ olarak bulundu (Tablo 1). Özen ve ark., ${ }^{[12]}$ AKS geçiren hastaların yaş ortalamasını 52.4 \pm 9.4 (erkek: $49.9 \pm 8.6$; kadın: 58.9 \pm 7.9 ) olarak bulmuştur. Bu çalışmayla bulgular benzerlik göstermektedir. Soeiro ve ark., ${ }^{[15]}$ ise AKS geçiren hastaların yaş ortalamasını, erkeklerde $60.3 \pm 11.6$, kadınlarda $64.6 \pm 10.4$ olarak bildirmiştir. Soeiro ve ark., ${ }^{[15]}$ daha ileri yaşlarda AKS saptanmışken; bizim çalışmamızda AKS yaşının 10 yaş daha düşük olduğu bulundu. Bu çalışmada risk faktörlerini doğru tanımlayabilmek amacıyla ilk kez AKS geçiren hastalar örnekleme alınırken, Soeiro ve ark., ${ }^{[15]}$ çalışmasında ise daha önce AKS geçiren hastalar da örnekleme dahil edilmiştir. Bu nedenle bulguların farklılık gösterdiği düşünüldü. Bununla birlikte erkeklerde 45, kadınlarda 55 yaş koroner arter hastalığı için risk faktörüdür. Bu çalışmada erkek hastaların $\mathrm{KAH}$ yaşından 10 yaş daha ileri bir yaşta akut koroner sendrom geçirdikleri tespit edildi. Kadınların ise $\mathrm{KAH}$ yaşıyla AKS geçirme yaşları eşit bulundu. Bu durum, literatürde de belirtildiği gibi kadınların erkeklere oranla daha geç yaşta $\mathrm{KAH}$ geliştiği, ${ }^{[16]}$ ancak literatürde bu konuda bir bulguya rastlanmazken bu çalışma verilerine göre daha hızlı AKS geçirdiklerini düşündürdü. Bu durumun ilerleyen yaşla birlikte kadınların hormonal durumlarındaki değişikliğe bağlı geliştiği sonucuna varıldı.

Hastaların çoğunluğunun hanesine giren toplam aylık gelir 2000-5000 TL arasından idi (Tablo 1). Bu bulgular AKS'lu hastaların büyük çoğunluğunun gelirinin yoksulluk sınırı içerisinde olduğunu göstermektedir. Türk Erişkinlerinde Kalp Hastalığı ve Risk Faktörleri (TEKHARF) çalışmasında düşük gelirin gerek bireye, gerekse topluma kronik hastalıklar açısından risk yüklediği bildirilmiştir. ${ }^{[6]}$ Bu bilgiden ve çalışmanın verilerinden yola çıkarak düşük gelir düzeyinin AKS geçirmede risk faktörü olduğu düşünüldü.

Sistemik hastalıklar açısından hastalar değerlendirildiğinde \%84'2'sinin sistemik hastalığı mevcut idi. KAH olan hastalardan yalnızca \%19.3'ü tanısını önceden bilmekteyken, \%80.7'si tanısını bilmemekteydi. Ülkemizde KAH riski yüksek olmasına rağmen, ${ }^{[17]}$ hastaların $\mathrm{KAH}$ farkındalıkları düşüktür. Bu sonuçlardan yola çıkarak KAH'na yönelik taramaların yetersiz olduğu ve hastaların AKS geçirdiklerinde ancak koroner arter hastalığı tanısı aldıkları düşünüldü.

Hastaların \%55'inin STEMI tanısı almış olduğu ve en sık uygulanan girişimin ise koroner arter stenti olduğu tespit edildi (Tablo 1). Baltacı ve ark., ${ }^{[10]}$ hastaların \%74.5'inin, Yağlı ve ark., ${ }^{[18]} \% 64$ 'ünün STEMI tanısı aldığını bildirmiştir. Hastaların KAH farkındalığının olmaması ve AKS hakkında bilgi sahibi olmamaları nedeniyle semptomlar ancak STEMI gibi ciddi bir klinik tabloya ulaştığında hastaneye başvurmalarından kaynaklandığı düşünüldü. Perkütan koroner girişim ilk olarak 1977 'de uygulanmış ve 1980 'lerin ortalarında, koroner arter baypass greftine alternatif olmuştur. Günümüzde miyokardiyal revaskülarizasyon birincil tedavi yöntemidir. ${ }^{[19]}$ Hastaların büyük çoğunluğunun STEMI tanısı almış olmalarına bağlı olarak koroner arter stenti uygulanması beklendik bir sonuçtur.

Hastaların \%82.5'inin ( $\mathrm{n}=99$ ) fiziksel aktivite yapmadığı, \%69.2'sinin ( $n=83$ ) ailesinde KAH öyküsünün olduğu, \%66.7'sinin ( $n=80)$ stresini kontrol etmede yetersiz kaldığı, \%56.7'sinin sigara içtiği, \%14.2'inin alkol kullandığı tespit edildi (Tablo 2). Yapılan çalışmalarda kadınların \%17.6'sının, erkeklerin ise \%45.8'inin sigara içtiği, ${ }^{[6]} \% 9.3^{\prime}$ ünün $(n=14)$ alkol tükettiği, ${ }^{[10]} \% 39.7$ 'sinin birinci derecede yakınların- 
dan erken yaşta (erkek hastalarda 55 kadın hastalarda 65 yaş altı) KAH öyküsünün olduğu, ${ }^{[10]} \% 72.3$ 'ünün fiziksel aktivite düzeyinin yetersiz olduğu, ${ }^{[20]}$ toplumun fiziksel aktivite oranının diğer yıllara oranla giderek düştüğü,, ${ }^{6]} \mathrm{KAH}$ olan bireylerin süreklilik anksiyete puanlarının yüksek oldu$\mathrm{ğu}^{[21,22]}$ bildirilmiştir. Tüm bu sonuçlar bizim çalışmamızla benzerlik göstermektedir. Akut koroner sendrom geçiren hastaların $\mathrm{KAH}$ risk faktörü olan, ${ }^{[23,24]}$ sigara içiciliği, birinci derece yakınlarında KAH öyküsü olması, fiziksel aktivite yetersizliği, stres gibi KAH risk faktörlerini yüksek oranlarda taşıdıkları sonucuna varıldı. Ancak bir diğer KAH risk faktörü olan alkol kullanımı oranı çalışmaya alınan hastalarda düşük bulundu. Alkol kullanımı oranının ölçülmesinde ülkemize özgü objektif değerlendirme araçlarına ihtiyaç olduğu düşünüldü. Bununla birlikte kadınların stresi kontrol etmede yetersiz kalma durumu erkeklere oranla yüksek bulundu ( $\mathrm{p}<0.05)$. Bayrak ve ark., ${ }^{[25]}$ kadınlarını stres algısını daha yüksek bulmuşlardır. Bulgular benzerdir. Sonuç olarak cinsiyet özelliklerine bağlı olarak KAH için risk faktörü olan stresin kadınlarda daha yüksek olduğu düşünüldü.

Kardiyovasküler hastalık açısından yüksek riskli olan bireylere, egzersiz eğitimi, stres yönetimi, psikososyal risk faktörleri konusunda danışmanlık, sağlıklı yaşam eğitimi ile medikal tedavinin birleştirilmesi önerilmektedir. ${ }^{[26]}$ Bir ESC kanıt projesi olan Hemşire Koordineli Multidisipliner, Aile Temelli Kardiyovasküler Hastalık Önleme Programı (Nurse-coordinated multidisciplinary, family-based cardiovascular disease prevention programme-EUROACTION) çalışmasında, etkin bir ikincil korumanın sağlanabilmesinde, hem hasta hem de aileyi içeren kapsamlı ve çok disiplinli programların gerektiği bildirilmiş ve bu amaçla hemşire kordineli eğitimlerin yapılması önerilmiştir. ${ }^{[27]}$

ATP III kılavuzunda ${ }^{[8]} \mathrm{KAH}^{\prime}$ dan korunmak için bildirilen hedef lipit parametreleri T-K seviyesi $\leq 200 \mathrm{mg} / \mathrm{dL}$, LDL seviyesi $\leq 100 \mathrm{mg} / \mathrm{dL}$, trigiliserid seviyesi $\leq 150 \mathrm{mg} / \mathrm{dL}$, HDL seviyesi $\geq 40 \mathrm{mg} / \mathrm{dL}$ şeklindedir. Bu çalışmada AKS geçiren bireylerin LDL düzeyleri hedef değerin üzerinde, $\mathrm{HDL}$ değerinin ise hedef değerin altındadır. Bu tablonun en önemli sebebinin toplumumuzda sağlıklı yaşam konusunda bilgi eksikliğinin olması ve sağlıklı yaşama ilişkin davranışların yeterince önemsenmemesi olarak düşünüldü. Dislipidemilerin Tedavisine İlişkin 2016 ESC/EAS Kılavuzu ${ }^{[28]}$ hastaların sağlıklı yaşam davranışlarına yönlendirilmesi açısından önemli bir kılavuzdur ve bu doğrultusunda hastaların sağlıklı yaşam davranışlarına yönlendirilmelidir.

Beden kitle indeksleri değerlendirildiğinde her iki cinsiyetinde beden kitle indeksi yüksek bulundu $\left(\mathrm{BKI}>25 \mathrm{~kg} / \mathrm{m}^{2}\right)$. Cinsiyete göre beden kitle indeksi karşılaştııılığında ise kadınların beden kitle indeksi erkeklere oranla yüksek bulundu ( $\mathrm{p}=0.004)$. Bayrak ve ark., ${ }^{[29]}$ kalp hastalarında yaptıkları çalışmada katıımcıların \%49'unun beden kitle indek$\operatorname{sinin} 25 \mathrm{~kg} / \mathrm{m}^{2}$ üstünde olduğunu belirtmişlerdir. Bulgular bu çalışmayla benzerlik göstermektedir. Soeiro ve ark., ${ }^{[15]}$ Brezilya'da AKS'lu 3.745 hastada (2.437 erkek ve 1.308 kadın) yaptıkları retrospektif, çok merkezli çalışmada kadınların beden kitle indeksini, erkeklere oranla düşük bulmuşlar$\operatorname{dır}(p<0.001)$. Bu çalışmayla farklı sonuçlar elde edilmesinin kültürel özelliklerin farklı olmasına bağlı olduğu düşünüldü. Beden kitle indeksinin $25 \mathrm{~kg} / \mathrm{m}^{2}$ ve üzerinde olması $\mathrm{KAH}$ için risk faktörü olarak kabul edilmektedir. Kardiyovasküler risk faktörü olan obezite prevalansının Türk kadınlarında yüksek, iki cinsiyette de artmakta olduğu bildirilmiş ve bu risk faktörünün toplumumuzdaki önemi vurgulanmıştır. ${ }^{[6]}$ Çalışmada AKS'lu hastalarda beden kitle indeksi kadınlarda daha yüksek olmakla birlikte her iki cinsiyette de $\mathrm{KAH}$ riski olarak kabul edilen $25 \mathrm{~kg} / \mathrm{m}^{2}$ ' nin üzerindedir.

Akut koroner sendromlu hastalarda $\mathrm{KAH}$ risk faktörlerinin görülme sıklığı cinsiyete göre karşılaştırıldığında, erkeklerde hiperkolesterolemi (\%92.2) birinci sırada yer alırken, kadınlarda stres ile birlikte ona çok yakın değerde bulunan beden kitle indeksinin yüksek olması en sık görülen $\mathrm{KAH}$ risk faktörü olarak bulundu (Tablo 3). Akbağ ve ark. [30] çalışmasında kadınların erkeklere oranla stres düzeylerinin daha yüksek olduğu bildirmişlerdir. Sonuçlar benzerdir. Aladağ ve ark., ${ }^{[31]}$ çalışmasında en sık görülen risk faktörünün kadınlarda HT (\%65.3), erkeklerde sigara kullanımı (\%53.3) olduğunu bildirmişlerdir. Aladağ ve ark. ${ }^{[31]}$ çalışmasında stresle ve beden kitle indeksiyle ilgili verilere rastlanmadı. Ayrıca bizim çalışmamızda ilk kez AKS geçiren hastalar çalışmaya dahil edildi. Aladağ ve ark. ${ }^{[31]}$ ise böyle bir dahil edilme kriteri belirtilmemiştir. Hastaların KAH ya da daha önce geçirilen bir AKS nedeniyle lipit metabolizmasına etkili ilaçlar kullanıyor olabilecekleri göz önünde alınarak risk faktörlerinin görülme sıklıklarının farklı olabileceği düşünüldü.

\section{Sonuç}

Bu çalışmada kadınların erkeklere kıyasla KAH risk faktörlerini (beden kitle indeksinin yüksek olması, stresi kontrol etmede yetersiz kalma durumu) daha yüksek oranlarda taşıdıkları bulundu. Ancak buna rağmen kadınların AKS geçirme durumu erkeklere göre daha düşük olduğu bulundu. AKS geçiren hastaların; cinsiyet, yaş, sistemik hastalık (HT, DM), sigara kullanma, yetersiz fiziksel aktivite, stres, dislipidemi, beden kitle indeksinin yüksek olması olan KAH risk faktörlerini taşıdıkları saptandı. Ayrıca düşük gelirli olmak, KAH'nın farkındalığının olmaması AKS geçirme riskini artır- 
dığı sonucuna varıldı. Bu sonuçlar doğrultusunda;

- Toplumdaki bireylerin koroner arter hastalığı ve AKS geçirme riski açısından rutin taranması,

- Toplumun KAH ve AKS farkındalığının artırılmasına yönelik projelerin ve eğitimlerin planlanması önerilebilir.

\section{Araştırmanın Sınırlılıkları}

Araştırmaya 2018- 2019 tarihleri arasında yalnızca verilerin toplandığı Salı, Perşembe ve Cuma günleri AKS ile başvuran hastalar örnekleme alındı. Ayrıca sosyodemografik özelliklerle ilgili bilgiler hastaların ifadeleriyle sınırlıdır.

Etik Kurul Onayı: Marmara Üniversitesi Tıp Fakültesi Klinik Araştırmalar Etik Kurulu; Protokol Kodu: 09.2018. 362; tarih: 04. 05.2018 .

Hakem Değerlendirmesi: Dış bağımsız.

Çıkar Çatışması: Yazarlar arasında herhangi bir çıkar çatışması bulunmamaktadır.

Yazarlık Katkıları: Konsept: A.K.Ş., Ş.E.A.; Dizayn: A.K.Ş., Ş.E.A.; Veri Toplama veya İşleme: A.K.Ş.; Analiz veya Yorumlama: A.K.Ş.; Literatür Arama: A.K.Ş.; Yazan: A.K.Ş.

\section{Kaynaklar}

1. Emik KY, Önal AE. 2009-2016 Yıllarında Türkiye'deki Ölümlerin Epidemiyolojik Yönden Incelenmesi ve Ölüm Bildirim Sisteminin Önemi. İstanbul Tıp Fakültesi Dergisi 2019;82(3):149-55.

2. Murray CJL. Institute for Health Metrics and Evaluation (IHME). Findings from the Global Burden of Disease Study 2017. Seattle, WA: IHME, 2018. p. 1-28.

3. Aydınalp A, Müderrisoğlu H. Akut Koroner Sendrom Tanımı ve Gelişimi. Ankara: Hacettepe Üniversitesi Hastaneleri Basım Evi; 2009. p.11-17.

4. Kotecha A, Rakhit RD. Acute coronary syndromes. Clinical Medicine 2016;16(6):43-8. [CrossRef]

5. Barstow C, Rice M, McDivitt JD. Acute Coronary Syndrome: Diagnostic Evaluation. Am Fam Physician 2017;95(3):170-7.

6. Onat $A, C a n, G$, Yüksel $H$, Ademoğlu $E$, Ünaltuna $N$, Kaya $A$, et al. TEKHARF 2017, Tıp Dün-yasının Kronik Hastalıklara Yaklaşımına Öncülük. İstanbul: Logos Tıp Yayınclık; 2017. p.1-244.

7. Ceylan Y, Kaya Y, Tuncer M. Akut Koroner Sendrom Kliniği ile Başvuran Hastalarda Koroner Arter Hastalığı Risk Faktörleri. Van Tıp Dergisi 2011;18(3):147-54.

8. Knuuti J, Wijns W, Saraste A, Capodanno D, Barbato E, Funck-Brentano C, et al. 2019 ESC Guidelines for the diagnosis and management of chronic coronary syndromes. Eur Heart J 2020;41 (3):407-77. [CrossRef]

9. Expert Panel on Detection, Evaluation, and Treatment of High Blood Cholesterol in Adults (Adult Treatment Panel III). Executive Summary of the Third Report of the National Choleste-rol Education Program (NCEP). JAMA 2001;285:2486-97. [CrossRef]

10. Baltacı D, Öztürk S, Durmuş İ, Kandiş H, Çelik Ş. Akut Koroner Sendrom Hastalarında Klinik Özelliklerin ve Transport Zama- nının Akut Koroner Sendrom Sınıflamasına Göre Karşılaştırıl-ması. Düzce Tıp Dergisi 2011;13(2):23-9.

11. Usta M, Sakin A, Sakin A, Çelik K, Öztürk S, Aylin FA, et al. Akut Koroner Sendromlu Hasta-larda Majör Risk Faktörlerinin ve Laboratuvar Parametrelerinin Değerlendirilmesi. Smyrna Tıp Dergisi 2015;2015(2):5-11.

12. Özen $M$, Serinken M, Yılmaz A, Özen Ş. Acil Servise Başvuran Akut Koroner Sendrom Tanılı Hastaların Sosyodemografik ve Klinik Özellikleri. Türkiye Acil Tıp Dergisi 2012;12(3):117-22.

13. Huang G, Wang D, Zeb I, Budoff MJ, Harman SM, Miller V, et al. Intra-thoracic fat, cardiometabolic risk factors, and subclinical cardiovascular disease in healthy, recently menopausal women screened for the Kronos Early Estrogen Prevention Study (KEEPS). Atherosclerosis 2012;221(1):198-205. [CrossRef]

14. Guo C, Zhang S, Zhang J, Liu H, Li P, Liu H, et al. Correlation between the severity of coronary artery lesions and levels of estrogen, hs-CRP and MMP-9. Exp Ther Med 2014;7(5):117780. [CrossRef]

15. Soeiro AM, Silva PGMBE, Roque EAC, Bossa AS, Biselli B, Leal TCAT, et al. Prognostic Differences between Men and Women with Acute Coronary Syndrome. Data from a Brazilian Registry. Arq Bras Cardiol 2018;111(5):648-53. [CrossRef]

16. Buğan B, Çelik T. Koroner Arter Hastalığı Risk Faktörleri. J Clin Anal Med 2014;5(2):159-63. [CrossRef]

17. Eray A, Set T, Ateş E. Yetişkin Bireylerde Kardiyovasküler Hastalık Riskinin Değerlendirilmesi. Türk Aile Hek Derg 2018;22(1):12-9. [CrossRef]

18. Yağlı VN, İnce Di, Sağlam M, Çalık Kütükçü E, Arıkan H. Akut Koroner Sendromlu Hastalar-da Anksiyete Ve Depresyonu Belirleyen Faktörler. Turk J Physiother Rehabil 2015;26(1):40-6.

19. Wijns W, Kolh P, Danchin N, Mario CD, Falk V, Folliguet T, et al. Miyokardiyal Revaskülari-zasyon Kılavuzu. Türk Kardiyol Dern Arş 2010;3:19-78.

20. Sevinç S, Akın H, Uzun Ö. Akut Koroner Sendromlu Hastalarda Pedigri Analizi ile Risk Faktör-leri Yaşam Kalitesi ve Hastalık İlişkisi. Turk J Cardiovasc Nurs 2018; 9(18):13-19. [CrossRef]

21. Şimşek AK, Şimşek T, Alpar ŞE. Açık kalp ameliyatlarında preoperatif eğitimin: postoperatif dönemde anksiyete ve iyileşme süreci üzerine etkisinin incelenmesi. Ege Üniversitesi Hemşirelik Fakültesi Dergisi 2018;34(3):45-62.

22. Sünbül $M$, Zincir SB, Durmus $E$, Sunbul EA, Cengiz FF, Kivrak T, et al. Anxiety and Depres-sion in Patients with Coronary Artery Disease. Klinik Psikofarmakoloji Bülteni 2013;23(4):34552. [CrossRef]

23. Switaj TL, Christensen SR, Brewer DM. Acute Coronary Syndrome: Current Treatment. Am Fam Physician 2017;95(4):232-40.

24. Reed-Poysden C, Gupta KJ. Acute coronary syndromes. BJA Education 2015;15(6):286-93. [CrossRef]

25. Bayrak B, Oğuz S, Arslan S, Candar B, Keleş S, Karagöz B, et al. Miyokard Infarktüsü Geçir-miş Hastalarda Algılanan Stresin Belirlenmesi. Turk J Card Nur 2019;10(23):129-37. [CrossRef]

26. Perk J, Backer GD, Gohlke H, Graham L, Reiner A, Verschuren $M$, et al. Avrupa Klinik Uygu-lamada Kardiyovasküler Hastalıklardan Korunma Kılavuzu (Versiyon 2012). Türk Kardiyol Dern 
Arş 2012;3:1-62.

27. Wood DA, Kotseva K, Connolly S, Jennings C, Mead A, Jones J, et al. Nurse-coordinated multidisciplinary, family-based cardiovascular disease prevention programme (EUROACTION) for patients with coronary heart disease and asymptomatic individuals at high risk of cardiovascular disease: a paired, cluster-randomised controlled trial. Lancet 2008;371(9629):19992012. [CrossRef]

28. Catapano AL, Graham I, Backe GD, Wiklund O, Chapman MJ, Drexel $\mathrm{H}$, et al. Dislipidemilerin Tedavisine Iliş̧kin 2016 ESC/EAS Kılavuzu. European Heart Journal 2016:37(39);2999-3058.

29. Bayrak B, Yıldırım G, Oğuz S, Sağaltıcı Ç, Doğanay E, Özdemir
F, et al. Kalp Yetersizliği Has-talarında Öz Bakımı Değerlendirme ve Etkileyen Risk Faktörlerin Belirlenmesi. Turk J Card Nurs 2019;10(23):114-21. [CrossRef]

30. Akbağ M, Sayıner B, Sözen D. Üniversite Öğrencilerinde Stres Düzeyi, Denetim Odağı ve Dep-resyon Düzeyi Arasındaki İlişki Üzerine Bir İnceleme. M.Ü. Atatürk Eğitim Fakültesi Eğitim Bilimleri Dergisi 2005;21:59-74.

31. Aladağ N, Özdemir M, Yurdaş M, Gümrükçüoğlu HA. Akut Koroner Sendrom ile Başvuran Hastala-rın Klinik Özellikleri, Risk Faktörleri ve Tedavi Yöntemleri. Van Tıp Derg 2019;26(4):50513. 